\title{
The influence of wet milling of aluminum and aluminum alloys powder screenings on the characteristics of the aluminum-based pastes
}

\author{
A. V. Egorov ${ }^{1}$, D. A. Kozlov ${ }^{2}$, Yu. B. Mamaeva ${ }^{3}$, A. K. Petrov ${ }^{3}$, A. V. Garshev ${ }^{1,2}$, P. V. Evdokimov ${ }^{1,2}$, \\ Ya. Yu. Filippov ${ }^{1}$, N. K. Orlov ${ }^{1}$, V. I. Putlayev ${ }^{1,2}$, A. V. Chetvertukhin ${ }^{3}$, I. Yu. Mikhailov ${ }^{4}$, \\ S. V. Polyakov ${ }^{5}$, A. A. Fedyanin ${ }^{3}$ \\ ${ }^{1}$ Lomonosov Moscow State University, Faculty of Chemistry, Leninskie gory, 1, building 3, Moscow, 119991, Russia \\ ${ }^{2}$ Lomonosov Moscow State University, Faculty of Materials Science, \\ Leninskie gory, 1, building 73, Moscow, 119991, Russia \\ ${ }^{3}$ Lomonosov Moscow State University, Faculty of Physics, Leninskie gory, 1, building 2, Moscow, 119991, Russia \\ ${ }^{4}$ LLC Light Materials and Technologies Institute, Leninskiy prospect, 6/21, Moscow, 119049, Russia \\ ${ }^{5}$ JSC Russian Aluminium Management, Vasilisy Kozhinoi str., 1, Moscow, 121096, Russia \\ garshev@inorg.chem.msu.ru, egorov@kge.msu.ru, chetvertukhin@nanolab.phys.msu.ru, ivan.mikhaylov@rusal.com
}

PACS 62.20.Qp

DOI 10.17586/2220-8054-2019-10-6-674-680

The milling of aluminum powders in non-aqueous solvents is used in the production of high-quality pigment pastes of flake shapes with thickness from some microns to hundreds of nanometers. In Russia, such pigments are not produced at a large scale, however, spherical powders made from aluminum and its alloys are manufactured. Starting the production of pigments from screenings of powder production will not only solve the problem of fine fractions disposal, but also reduce the cost of the target fractions powders. The fraction of powders with an average d50 of less than $\sim 20 \mu \mathrm{m}$ should be disposed. In this research, by varying the laboratory conditions, the parameters for milling screenings of A8 aluminum powder, AK9ch and 1201 aluminum alloys were selected. The milling was performed in non-aqueous solvents: a highly refined commercial petroleum solvent and liquid paraffin oil. The prospects of using wet milling for the manufacture of pigment pastes from alloys has been demonstrated including average thicknesses of the flakes about $40-80 \mathrm{~nm}$. Thus, it has been demonstrated that wet and bead grindings lead to thinning of metal powder particles to thicknesses of less than $100 \mathrm{~nm}$.

Keywords: aluminum alloy, screenings of powder productions, wet milling.

Received: 12 August 2019

Revised: 30 November 2019

\section{Introduction}

Spherical-shaped aluminum particle powders are used as powders and pastes in the production of blowing agents for autoclaved aerated concrete and pigments for paints. In the first case, the powder is milled in ball mills, by introducing an oiling additive and by blowing a nitrogen-oxygen mixture with a controlled oxygen content through a mill. In the manufacture of pigment pastes, the powder is milled in a non-aqueous solvent using an oiling additive. By varying the conditions and the milling medium, pigment pastes for various purposes are obtained. Thus, depending on the location of the aluminum powder flakes in the surface layer of the paint coating (pigment flotation), as well as on the aspect ratio of the pigment particle, the reflective properties of the coating ("metallic" effect, graininess, irisation) and its mechanical properties (adhesion, strength, abrasion, hiding power) change significantly. Varnish-and-paint coatings even with the aluminum pigment content of $18 \%$ are capable of reflecting up to $70 \%$ of infrared radiation and can be used for energy-saving purposes. A promising area for aluminum-containing pigment application is the production of varnish-and-paint materials for the automotive industry (paints with a "metallic" effect) and printing (can $\&$ coin type of paints for metallic parts of labels (brochures, posters, coatings on plastics, etc.) for which the numerical value of D50 for flakes and discs is in the range from 10 to $35 \mu \mathrm{m}$ [1]. The growing production of aluminum powders by the "atomization" method [2] has made it possible to consider the screenings from "atomized" powders as the source of aluminum instead of the aluminum foil. This have given rise to the development of a technology for the production of a number of pigments with a "metallic" effect with new consumer properties. Thus, an experimental study was conducted in [3] aimed at determining the optimal milling parameters for producing pigment pastes from aluminum during wet milling. Obtaining flakes from spherical aluminum particles requires a special approach during milling and this process is described by the two-stage model: at the first stage of milling, the material absorbs energy required for the formation of disc-shaped plate-like particles from the initial spherical ones and at the second stage, the portion of energy is required for the milling of disc-shaped plates into smaller ones with irregular shapes. 
There are different methods of manufacturing aluminum plate-like particles, such as stamping, dry and wet milling in ball mills, the use of attritors, and vibration milling [4-6]. When using stamping milling, aluminum powder is abraded with a hammer under an aerobic atmosphere, the powder moves continuously with an air stream and then the fractionation takes place. However, this method is not widespread because of its explosiveness. Horizontal ball mill is used more often in the production of plate-shaped aluminum flakes, as it is more suitable for large-scale production and allows one to achieve good dispersion of the resulting aluminum product. Wet milling is most often used to produce paints and inks; organic solvents are used as a milling medium. The following factors influence the milling process: the size of the milling media, the number of intermediate stops during milling, the amount of oiling additive. The advantages of wet milling are [7]: reduction of particle agglomeration compared to dry milling; no loss of ground material; there is no risk of spontaneous oxidation of small particles; air purification devices are not required; heat transfer is improved.

Today, this technology is widely used in various industries [8,9]: varnish-and-paint, chemical, pharmacological, fertilizer production, food production, paper manufacturing, bioengineering, nanotechnology and ceramic production. Ball and bead mills are widely used in laboratory modeling of the wet milling process. The use of bead wet milling allows one to obtain a product with a smaller particle size compared with milling in ball mills. Bead mills of both horizontal [7,8] and vertical design [9] are used. In a horizontal bead mill, in continuous operation, the suspension of the product being milled is pumped through the milling chamber. The running of the mill rotor makes the beads move, which, in turn, crushes the particles of a material. At the end of the work, the suspension of material is drained from the mill. Unlike a ball mill, which is filled with $\sim 40$ vol.\% of balls and crushed material, the filling of a bead mill with milling media reaches $85 \%$ by volume and the rest space is filled with crushed material suspended in a solvent. The milling bodies are separated from the crushed powder using a sieve cartridge or slot; the size of this slot does not exceed the half of the milling body size. The milling chamber as well as the rotor can also be cooled during the milling process by a special circuit which is necessary for temperature sensitive materials, since most of the energy transferred for the milling is transformed to heat. It should be noted that extremely high milling energy intensities are characteristic for bead mills in comparison with ball mills. For this reason, due to the various mechanical properties of the alloys, it is viable to carry out milling both in a bead mill and a ball mill when producing pigment pastes from screenings of A8-grade aluminum powders, AK9ch and 1201 alloys.

\section{Experimental part}

In this work, the screenings of the A8-grade aluminum, AK9ch and 1201 aluminum alloys were used, which were obtained by separation of the powders produced by gas atomization technique under nitrogen atmosphere with a small amount of oxygen for passivation. The powders of the alloys were obtained at Volgograd aluminum factory (United Company RUSAL). The extraction of the fractions from the screenings of the aluminum powders and aluminum-based alloys was performed on the standard equipment for the obtaining of the Company's products with the average d50 value of $\sim 2 \mu \mathrm{m}$ and $\sim 5 \mu \mathrm{m}$, respectively.

The powders and the milling products were studied by scanning electron microscopy (SEM) and X-ray spectral microanalysis by the LEO SUPRA 50 VP instrument (Zeiss, Germany) equipped with energy-dispersive detector XMAX 80 and INCA software (Oxford Inst., United Kingdom). The samples were analyzed at an acceleration voltage up to $20 \mathrm{keV}$ at the magnification of up to $\times 10000$ using the "in point" spectra collecting mode when analyzing chemical composition of the materials after milling, and "in area" mode when analyzing chemical composition of the starting powders. The elemental composition package was calculated in semi-automated regime using INCA Energy+ software program (Oxford Inst., United Kingdom).

X-ray diffraction (XRD) patterns were collected using a Rigaku D/MAX 2500 diffractometer $(\theta / 2 \theta$ BraggBrentano reflection geometry) with a scintillation counter. All the measurements were performed with $\mathrm{CuK} \alpha_{1,2}$ radiation generated on a rotating $\mathrm{Cu}$ anode $(50 \mathrm{kV}, 250 \mathrm{~mA})$ and monochromatized by a curved graphite [002] monochromator placed at the reflected beam. The XRD patterns were collected in the 5-90 $2 \theta$ range with a $0.02^{\circ}$ step and at least $0.5 \mathrm{~s} / \mathrm{step}$. To reduce the undesirable background intensity, all samples were investigated on monocrystalline $\mathrm{Si}$ holders oriented by [510].

The particle-size distribution in the starting alloy powders and milling products was analyzed by static light scattering using laser analyzer of particle sizes Analyzette 22 (Fritsch, Germany) with ultrasound treatment.

The milling of the powders was performed in a horizontal mill of an original construction (LLC "Technocenter", Russia) in the crushing cylinder with the diameter of $210 \mathrm{~mm}$, and in a bead mill 01-HD (Union Process, USA) equipped with a pin shaft. The milling in the bead mill was performed by addition of $80 \mathrm{~g}$ aluminum powder or aluminum alloy; $1600 \mathrm{~g}$ of steel balls with the diameter of $1 \mathrm{~mm} ; 160 \mathrm{~g}$ of paraffin oil and $8 \mathrm{~g}$ of an oiling additive to the milling chamber. The rotation frequency of the pin shaft was $500 \mathrm{rpm}$, the milling chamber was forcedly cooled 
with water of ambient-temperature. The test samples were collected at 10, 30, 60, 90, 120, 180, 240, and 300 minutes after milling initiation.

In a horizontal mill of the original construction (LLC "Technocenter", Russia), the milling was performed by addition of 150-250 ml of aluminum or aluminum alloy powder with a bulk density from 0.4 to $0.7 \mathrm{~g} / \mathrm{cm}^{3}, 1500-$ $2400 \mathrm{ml}$ of steel balls with the diameter of $5 \mathrm{~mm}, 900-1350 \mathrm{ml}$ of paraffin oil or a highly refined commercial petroleum solvent with a distillation temperature of $180-230^{\circ} \mathrm{C}$, and up to 3 vol. $\%$ of an oiling additive to the crushing cylinder. The rotation frequency of the crushing cylinder was varied from 65 to $95 \mathrm{rpm}$. The cylinder was cooled forcedly with water of an ambient temperature. The test samples were collected at 24, 40, and 60 hours after the starting of the milling.

Using the milling products, the colorings were obtained, for which the values of the flop index (FI) were determined. The measurements were performed using BYK-mac-i spectrophotometer (BYK Gardner GmbH, Germany). The colorings were made on the $100 \times 140 \mathrm{~mm}$ cards ISISTEM (Ideale Sistema LTD U.K, United Kingdom) and LENETA (Leneta Company, USA). For this, the mixtures of varnish, solidifier and the milling products were prepared. The content of the milling products in mixtures was varied from 5 to $50 \mathrm{vol} . \%$. The mixture was applied onto the cards as a layer with a fixed-thickness in the range from 9 to $50 \mu \mathrm{m}$ using a rod applicator.

\section{Results and discussion}

The results of the studying of the initial powders by scanning electron microscopy and static light scattering, have proved the attribution of the aluminum and aluminum-based alloys powders to the products with the average particle size of $\sim 2 \mu \mathrm{m}$ and $5 \mu \mathrm{m}$, respectively. The SEM image (Fig. 1) shows the A8-grade aluminum alloy with the average particle size of $\sim 2 \mu \mathrm{m}$, and according to static light scattering the $\mathrm{d} 10, \mathrm{~d} 50$, and $\mathrm{d} 90$ values for this product are $300 \mathrm{~nm}, 1.6 \mu \mathrm{m}, 3.4 \mu \mathrm{m}$, respectively. Moreover, the fraction of nanosized particles does not exceed a few percent. Fig. 2 contains the SEM image of A8-grade aluminum powders with the average particle size of $\sim 5 \mu \mathrm{m}$, and the static light scattering for this product reveals the $\mathrm{d} 10, \mathrm{~d} 50$, and $\mathrm{d} 90$ values of $2.4 \mu \mathrm{m}, 5.6 \mu \mathrm{m}$, and $12.6 \mu \mathrm{m}$, respectively. According to the EDX microanalysis, the chemical composition of the AK9ch and 1201 aluminum alloy powders satisfies the requirements of GOST 4784-97.

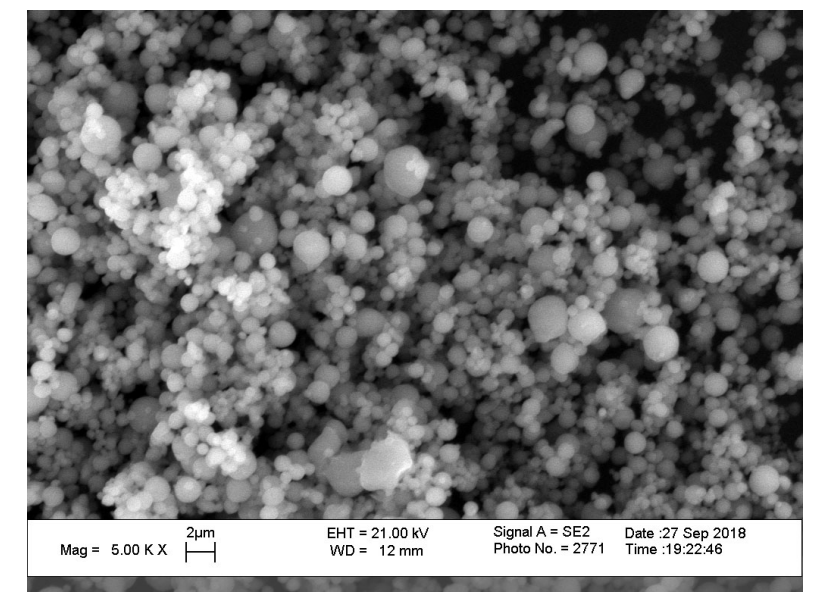

FIG. 1. SEM image of the A8-grade aluminum powder with the average particle size of $\sim 2 \mu \mathrm{m}$

For the milling of the A8-grade aluminum powder with the average particle size of $\sim 2 \mu \mathrm{m}$ as well as of $\sim 5 \mu \mathrm{m}$ in the ball mill under optimal values of the milling parameters, the maximal d50 values for the products are achieved after the milling during the period from 24 to 48 hours and are equal to $8.5 \mu \mathrm{m}$ for the A8-grade aluminum powder with the particle size of $\sim 2 \mu \mathrm{m}$, and $10.7 \mu \mathrm{m}$ for for the A8-grade aluminum powder with the particle size of $\sim 5 \mu \mathrm{m}$. With increased milling time, the d50 values decrease - after milling for 60 hours, the d50 have reduced to $6.7 \mu \mathrm{m}$ and $9.2 \mu \mathrm{m}$, respectively. The results of the SEM analysis of the A8-grade aluminum powder (the average particle size is $\sim 5 \mu \mathrm{m}$ ) after the milling during 60 hours in the ball mill are presented in Fig. 3. According to static light scattering, the $\mathrm{d} 10, \mathrm{~d} 50$, and $\mathrm{d} 90$ values for this sample are $2.8,9.2$, and $19.1 \mu \mathrm{m}$, respectively. When the A8-grade aluminum powders were milled in the bead mill, the maximum d50 values for the obtained products were achieved after milling for 90-120 minutes and are equal to $7.9 \mu \mathrm{m}$ for the A8-grade aluminum powder with the particle size of $\sim 2 \mu \mathrm{m}$, and $10.2 \mu \mathrm{m}$ for the powder with the particle size of $\sim 5 \mu \mathrm{m}$. A decrease in the d50 values exceeding $1 \mu \mathrm{m}$ at long milling times has not been observed. 


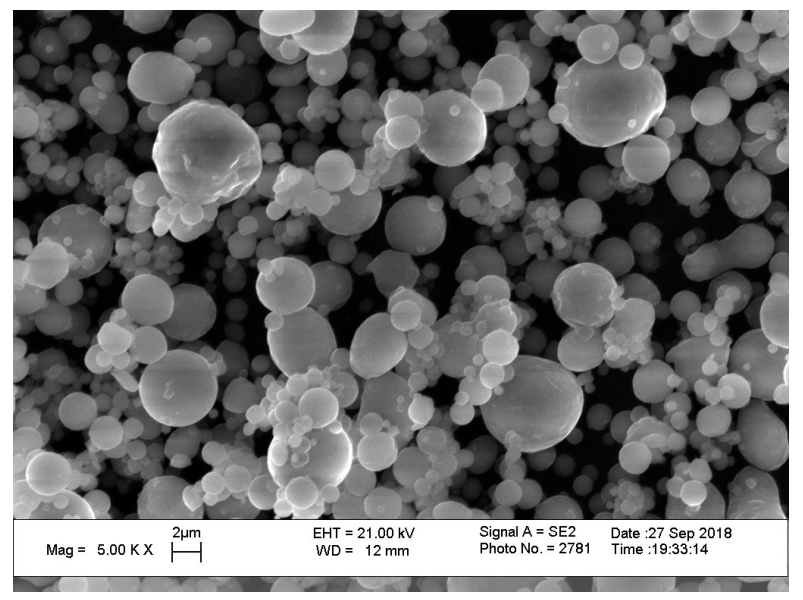

FIG. 2. SEM image of the A8-grade aluminum powder with the average particle size of $\sim 5 \mu \mathrm{m}$

According to SEM, the particle thicknesses after wet grinding do not exceed hundreds of nanometers, which leads to the unique optical properties of paints based on the obtained powders.

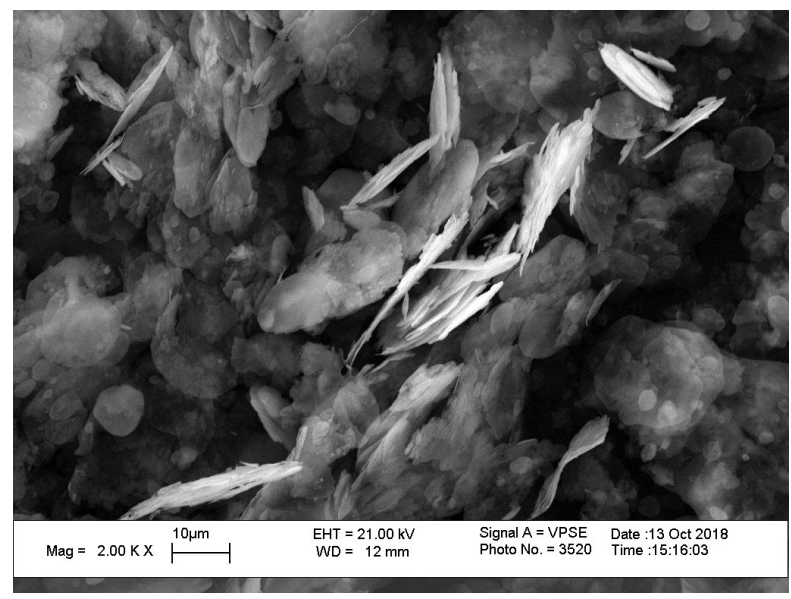

FIG. 3. SEM image of the A8-grade aluminum powder with the average particle size of $\sim 5 \mu \mathrm{m}$ after milling in the ball mill

For the milling of 1201 alloy powder with the average particle size of $\sim 5 \mu \mathrm{m}$, under the optimal values of milling parameters, the maximum d50 value is achieved after the milling for 24 hours and is equal to $9.3 \mu \mathrm{m}$. With an increase in the milling time, the d50 value for the products decreases - after the milling for 60 hours it was reduced to $4.9 \mu \mathrm{m}$.

The AK9ch alloy powder with the average particle size of $\sim 5 \mu \mathrm{m}$ failed to be milled in the ball mill under variation of different milling parameters. When milled in the bead mill, the maximal d50 value for the same powders was achieved after milling for 300 minutes and is equal to $9.2 \mu \mathrm{m}$ (the values were measured after milling for 10, 30, 60, 90, 120, 180, 240 and 300 minutes). The SEM image of the milling product obtained from AK9ch alloy powder with the average particle size of $\sim 5 \mu \mathrm{m}$ after the milling during 300 minutes in the bead mill is presented in Fig. 4. According to static light scattering, the values of d10, d50, d90 for this sample are 3.4, 9.2, and $17.0 \mu$ m, respectively.

The typical appearance of the coloring obtained using aluminum and aluminum-based alloys powder milling products is shown in Fig. 5. This coloring was obtained on the base of milling products prepared from AK9ch alloy with the average particle size of $\sim 5 \mu \mathrm{m}$ ground in a bead mill for 300 minutes. The flop index (FI) was calculated during studying of light reflection on the coloring:

$$
F I=\frac{2.69 \cdot\left(L_{15}-L_{110}\right) \cdot 1.11}{L_{45} \cdot 0.86}
$$

where $L$ - the lightness parameter, the value of which is varied from 0 - the reflection from the darkest color, to 100 - the reflection from the white standard, $L_{15}, L_{45}, L_{110}$ - the values of $L_{*}$ obtained at the observation angles of $15^{\circ}$, 


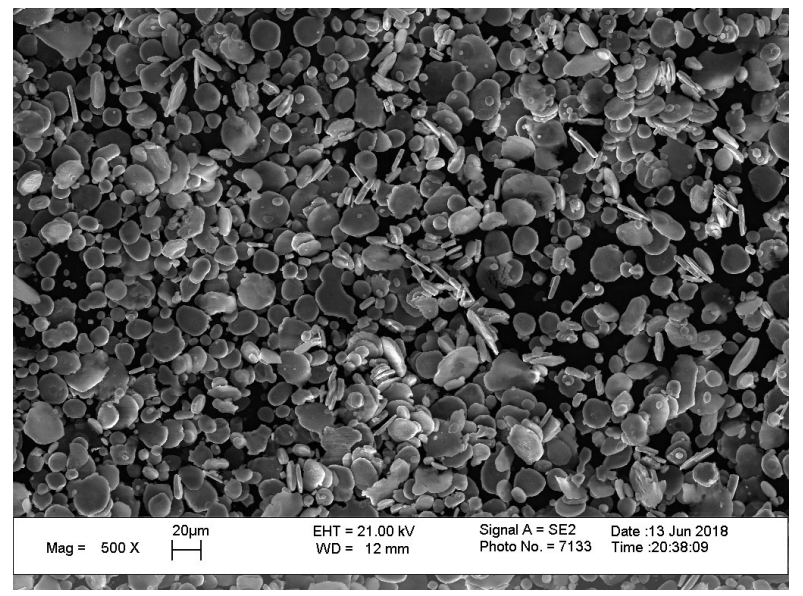

FIG. 4. SEM image of the AK9ch alloy powder with the average particle size of $\sim 5 \mu \mathrm{m}$ after milling in the bead mill

$45^{\circ}, 110^{\circ}$ respectively. The observation angle is measured from the direction of specular reflection towards the normal to the sample surface. For all the pigments with the "metallic" effect the value of FI exceeds 0, but for the most of the modern pigments this parameter ranges from 7 to 19 units. The maximum FI values for the samples based on milling products obtained in ball mills have been observed when the products were milled during 48 hours. Thus, for the milling products obtained from A8-grade aluminum with the average particle diameter of $\sim 5 \mu$ m, the maximum FI value is 15.0 units, and for the milling products obtained 1201 aluminum alloy, with the average particle size of $\sim 5 \mu \mathrm{m}$, the FI is 13.2 .

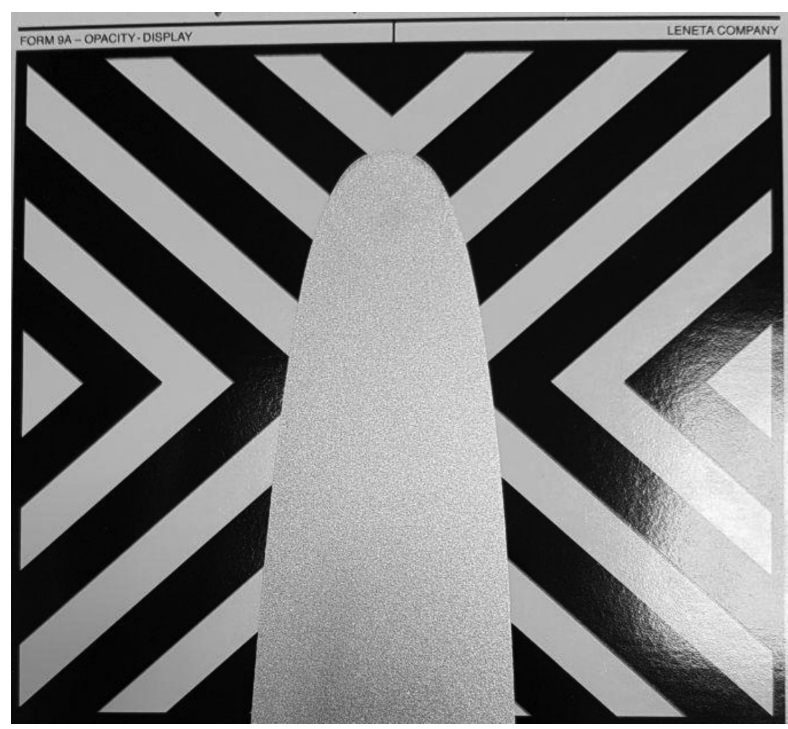

FIG. 5. The typical appearance of the coloring (the coloring prepared using the milling products of AK9ch alloy powder with the average particle size of $\sim 5 \mu \mathrm{m}$ )

The milling in a bead mill also allows to obtain the product for the preparation of coloring of materials with the FI corresponding to pigments with the "metallic" effect. Thus, for the milling products obtained from A8-grade aluminum with an average particle size of $\sim 2 \mu \mathrm{m}$, the FI is 15.0 units, for products obtained from the A8-grade aluminum with an average particle size of $5 \mu \mathrm{m}$, the FI is 10.0 units. And in case of the milling products obtained from AK9ch alloy with an average of $\sim 5 \mu \mathrm{m}$, the FI is 15.7. These values correspond to the current FI values for pigments with the "metallic" effect.

The achievement of such values of the flop index is possible due to the fact that under the selected milling conditions, the thickness of aluminum flakes is less than $100 \mathrm{~nm}$, which is confirmed by scanning electron microscopy (Fig. 6) and crystallite sizes calculated according to X-ray diffraction data. 

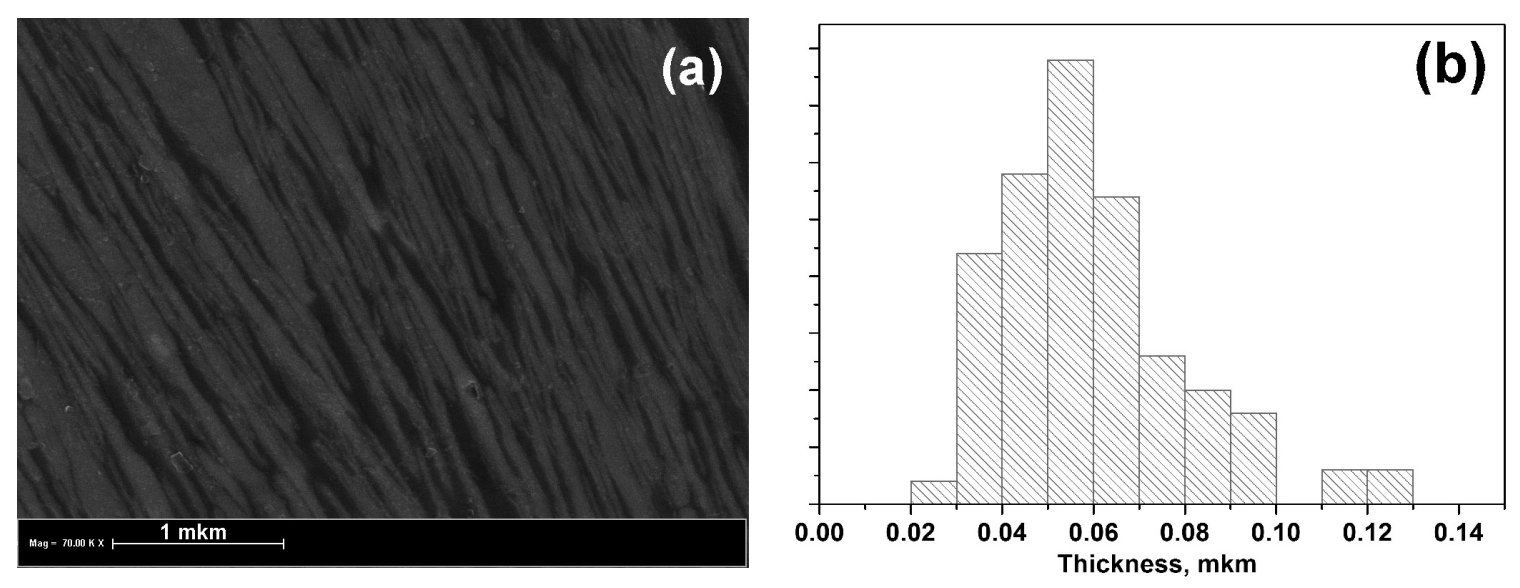

FIG. 6. SEM image of A8 flakes (wet milling) in resin after polishing - (a) and thickness size distribution of the individual flakes - (b)

According to X-ray diffraction data (Fig. 7), the crystallite sizes calculated by the Scherrer formula after bead milling are $83 \pm 9 \mathrm{~nm}$ and $80 \pm 4 \mathrm{~nm}$ for A8 and AK9 respectively. Wet milling results in smaller crystallite sizes $65 \pm 4 \mathrm{~nm}$ and $43 \pm 2 \mathrm{~nm}$ for the A8 and AK9 alloys respectively.

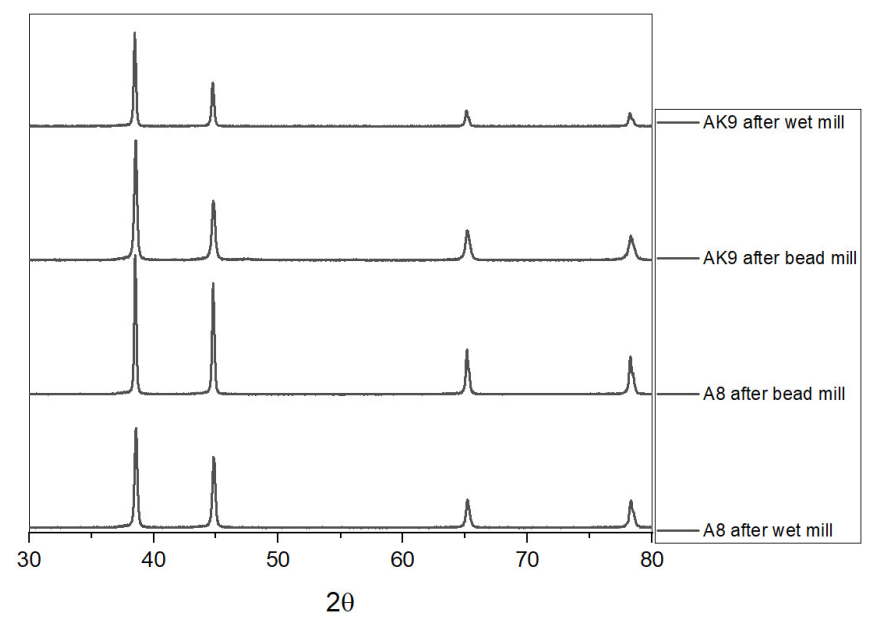

FIG. 7. XRD patterns of A8 and AK9 samples after wet and bead milling

\section{Conclusions}

The milling of screenings of aluminum powders and aluminum-based alloys using horizontal ball and bead mills can be used for obtaining of pigments and pigment pastes possessing "metallic" effect with the parameters corresponding to the industrially manufactured pastes. The prospects of using a wet milling technique for the manufacture of pigment pastes from alloys has been demonstrated including average thicknesses of the flakes about $40-80 \mathrm{~nm}$. Thus it has been demonstrated that wet and bead grindings lead to thinning of metal powder particles to thickness less than $100 \mathrm{~nm}$. The milling of alloys powders is reasonable to perform in bead mills exhibiting higher striking energy in comparison with ball mills.

\section{Acknowledgment}

This work was performed in Lomonosov Moscow state University, the General contractor of the R\&D studies, within of the Contract No PMSh-218-2017/01 dated 09.02.2017 at the financial support of Ministry of Education and Science of the Russian Federation according to the Agreement No 075-11-2018-196 dated 28.04.2017 (internal contract number 03.G25.31.0248). The equipment purchased within the Moscow State University Development Program was used in the present work. 


\section{References}

[1] Bosch W., Cuddemi A. Optimisation of the shear stability of aluminium pigmented waterborne basecoats. Progress in Organic Coatings, 2002, 44(3), P. 249-257.

[2] Garshev A.V., Kozlov D.A., Evdokimov P.V., Filippov Ya. Yu., Orlov N.K., Putlyaev V.I., Chetvertukhin A.V., Petrov A.K. Analysis of Aluminum Alloy Powders for Additive Manufacturing Fabricated by Atomization. Inorganic Materials: Applied Research, 2019, 10(4), P. 901-905.

[3] Svěrák T., Bulejko P., Krištof O., Kalivoda J., Horský J. Covering ability of aluminum pigments prepared by milling processes. Powder Technology, 2017, 305(1), P. 396-404.

[4] Seong-Hyeon Hong, Dong-Won Lee, Byoung-Kee Kim. Manufacturing of aluminum flake powder from foil scrap by dry ball milling process. Journal of Materials Processing Technology, 2000, 100(1-3), P. 105-109.

[5] Watanabe R., Hashimoto H., Lee G.G. Computer Simulation of Milling Ball Motion in Mechanical Alloying. Materials Transactions, JIM, 1995, 36(2), P. 102-109.

[6] Seong-Hyeon Hong, Byoung-Kee Kim. Effects of lifter bars on the ball motion and aluminum foil milling in tumbler ball mill. Materials Letters, 57(2), P. 275-279.

[7] Hoffl K. Zerkleinernngs- und Klassiermaschinen. Springer-Verlag, Berlin, Heidelberg, New York, Tokyo, 1986,275 p.

[8] Pahl M.H. Zerkleinerungstechnik. Verlag TÜV Rheinland, Köln, 1991, P. 283-317.

[9] Kwade A., Schwedes J. Wet Comminution in Stirred Media Mills. KONA Powder and Particle Journal, 1997, 15, P. 91-101. 